This item was submitted to Loughborough's Research Repository by the author.

Items in Figshare are protected by copyright, with all rights reserved, unless otherwise indicated.

\title{
Burning syngas in a high swirl burner: effects of fuel composition
}

PLEASE CITE THE PUBLISHED VERSION

http://dx.doi.org/10.1016/j.ijhydene.2013.05.021

PUBLISHER

(c) Elsevier

VERSION

AM (Accepted Manuscript)

LICENCE

CC BY-NC-ND 4.0

REPOSITORY RECORD

Ranga-Dinesh, K.K.J., K.H. Luo, M.P. Kirkpatrick, and W. Malalasekera. 2019. "Burning Syngas in a High Swirl Burner: Effects of Fuel Composition”. figshare. https://hdl.handle.net/2134/12630. 
This item was submitted to Loughborough's Institutional Repository (https://dspace.lboro.ac.uk/) by the author and is made available under the following Creative Commons Licence conditions.

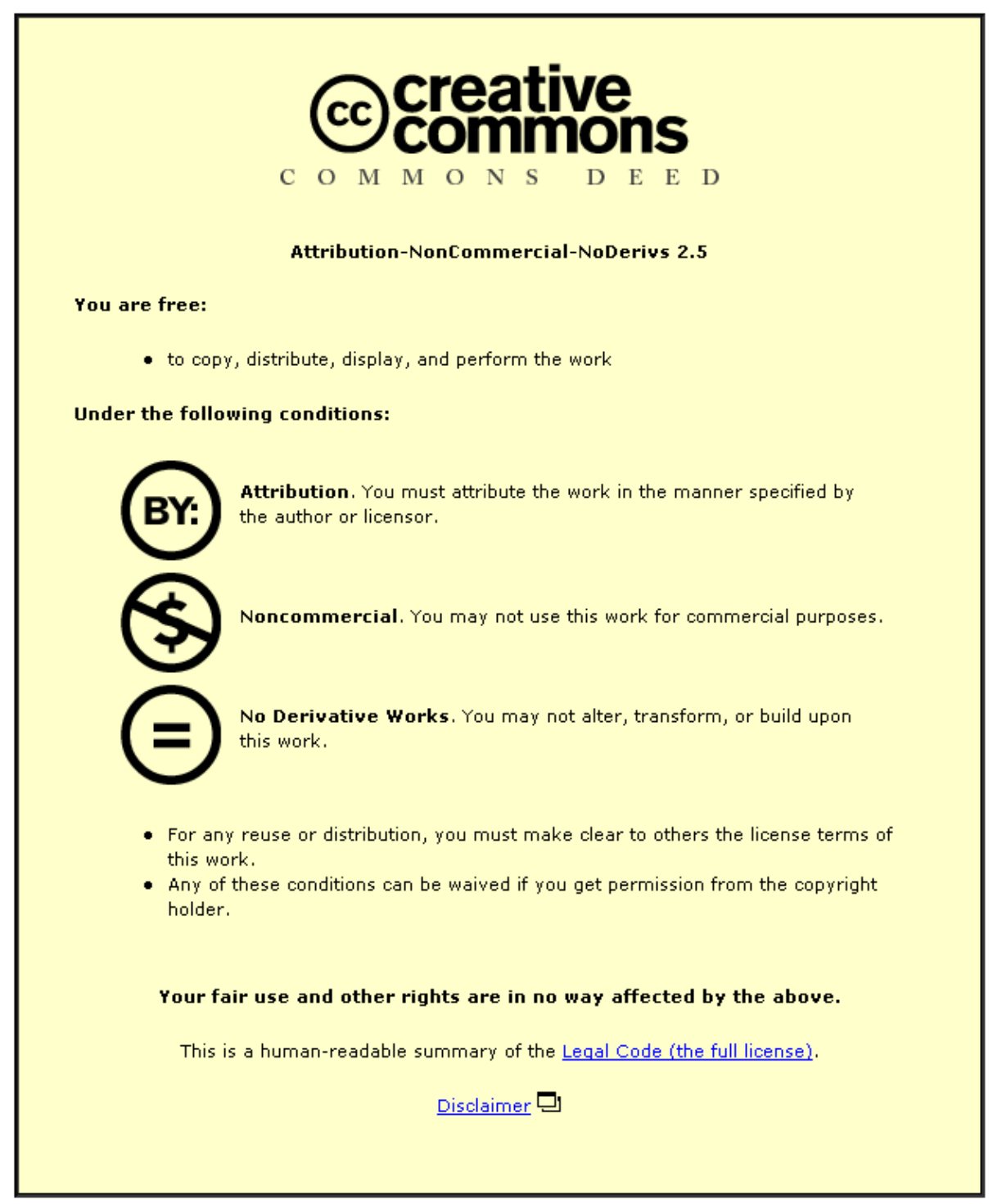

For the full text of this licence, please go to: http://creativecommons.org/licenses/by-nc-nd/2.5/ 


\section{BURNING SYNGAS IN A HIGH SWIRL BURNER: EFFECTS OF FUEL COMPOSITION}

\section{K.K.J.Ranga Dinesh ${ }^{1}$, K.H. Luo ${ }^{1}$, M.P.Kirkpatrick ${ }^{2}$, W.Malalasekera ${ }^{3}$}

1. Energy Technology Research Group, Faculty of Engineering and the Environment, University of Southampton, Southampton, SO17 1BJ, UK.

2. School of Aerospace, Mechanical and Mechatronic Engineering, The University of Sydney, NSW 2006, Australia.

3. Wolfson School of Mechanical and Manufacturing Engineering, Loughborough University, Loughborough, Leicestershire, LE11 3TU, UK.

Corresponding Author: K.K.J.Ranga Dinesh, Energy Technology Research Group, Faculty of Engineering and the Environment, University of Southampton, Southampton, SO17 1BJ, UK.

Email: Dinesh.Kahanda-Koralage@soton.ac.uk

Tel: + 44 (0) 2380598301

Revised Manuscript Prepared for the International Journal of Hydrogen Energy

May 2013 


\begin{abstract}
Flame characteristics of swirling non-premixed $\mathrm{H}_{2} / \mathrm{CO}$ syngas fuel mixtures have been simulated using large eddy simulation and detailed chemistry. The selected combustor configuration is the TECFLAM burner which has been used for extensive experimental investigations for natural gas combustion. The large eddy simulation (LES) solves the governing equations on a structured Cartesian grid using a finite volume method, with turbulence and combustion modelling based on the localised dynamic Smagorinsky model and the steady laminar flamelet model respectively. The predictions for $\mathrm{H}_{2}$-rich and CO-rich flames show considerable differences between them for velocity and scalar fields and this demonstrates the effects of fuel variability on the flame characteristics in swirling environment. In general, the higher diffusivity of hydrogen in $\mathrm{H}_{2}$-rich fuel is largely responsible for forming a much thicker flame with a larger vortex breakdown bubble (VBB) in a swirling flame compare to the $\mathrm{H}_{2}$-lean but CO-rich syngas flames.
\end{abstract}

Key Words: Hydrogen, Syngas, Swirl, Vortex breakdown, Combustion, LES 


\section{Introduction}

Fundamentally all fossil hydrocarbon resources are non-renewable and a valuable gift from nature, and thus it is important to develop more efficient and effective ways to utilise these energy resources for sustainable development. Development of clean combustion technology would allow continued use of hydrocarbon fossil storage in the world without substantial emissions of greenhouse gasses such as carbon dioxide $\mathrm{CO}_{2}[1]$. Such clean combustion technology will rely on combustion of synthesis gas or syngas, which is mainly a mixture of hydrogen $\left(\mathrm{H}_{2}\right)$ and carbon monoxide ( $\left.\mathrm{CO}\right)$ [2].

There is growing interest in the combustion of syngas for more sustainable and cleaner power generation. One of the main current interests in hydrogen and syngas usage is the integrated gasification combined cycle (IGCC) process for electricity generation compared to traditional power generation system such as coal combustion [3-4]. Ultimately IGCC systems will be capable of reaching efficiencies of $60 \%$ with near-zero pollution. The unique advantages of IGCC systems have led to potential applications of gasification technologies in industry because gasification is the only technology that offers both upstream (feedstock flexibility) and downstream (product flexibility) advantages. Because they operate at higher efficiency levels than conventional fossil-fueled power plants, IGCC systems emit less $\mathrm{CO}_{2}$ per unit of energy. They are also well suited for application of future technologies to capture and sequester $\mathrm{CO}_{2}[5-6]$.

In a typical IGCC plant, fuel is produced from a gasification process and burned with compressed air in a gas turbine to produce high-pressure hot gas. The high-pressure hot gas is expanded through the turbine to generate electric power. However, developing technology relevant to practical applications such as gas turbines, boilers and furnaces capable of 
combusting $\mathrm{H}_{2}$-rich and CO-rich syngas requires understanding of more fundamental combustion properties [7]. Since the operability issues of burning syngas fuels in these applications generally involve complex, poorly understood interactions between swirling flow dynamics, it is necessary to establish a framework for the combustion characteristics of syngas fuels particularly in the presence of swirl [8].

Swirl has been commonly used for the stabilisation of high intensity combustion which acts as a source to improve flame stability, reduce combustion lengths, ensure minimum maintenance and extend life for the unit [9]. Unlike the jet flames, most significant effects of swirling flow are produced by recirculation. Numerous experimental and theoretical investigations with the aim of contributing to the understanding of swirl stabilised combustion systems have been reported over the past three decades, which have mainly focused on instabilities and onset of vortex breakdown in combustion systems [10-12]. Swirl has two roles in a combustor. In the combustor, it creates features such as jet precession, recirculation, vortex breakdown (VB) and a coherent structure referred to the precessing vortex core (PVC) [13]. In combustion systems, these phenomena can promote coupling between heat release, flow dynamics and acoustics and control most aspects of the flame including heat release rate, flow properties, flame evolution and emissions [14]. Therefore elucidating the underlying combustion characteristics of swirling flames has been the central focus of fundamental research particularly on hydrocarbon combustion.

Numerical simulation has the potential for closing the gap between theory and experiment and enabling dramatic progress in combustion science and technology [15]. The predictive capabilities of numerical models is advancing rapidly, and future research will further increase the accuracy and efficiency of these computational tools, ultimately leading over the next decade to the generalisation of computer-aided design and optimisation as a fundamental 
engineering tool. The large eddy simulation (LES) technique is widely accepted as a potential numerical tool to simulate turbulent combustion problems corresponding to laboratory and practical scale configurations [16-17]. In LES, the large scale turbulence structures are directly computed and small dissipative structures are modelled. State-of-the-art numerical computations have been reported in literature which demonstrates the ability of LES to capture the unsteady flow field in complex swirl configurations including multiphase flows and combustion processes such as gas turbine combustion, internal combustion engines, industrial furnaces and liquid-fueled rocket propulsion [18-20]. Other investigations including validation of LES calculations for a model gas turbine combustor [21] and more complex General Electric aircraft engines and Pratt and Whitney gas turbine combustors were also reported [22-23]. More investigations on other important aspects of LES based combustion calculations such as effect complex mesh resolution [24] and ignitability characteristics [25] for gas turbine combustion were also carried out.

While the flame characteristics and stabilisation mechanisms of swirl stabilised systems have been fairly well investigated for conventional hydrocarbon-air systems, not much is known about the characteristics of alternative gaseous fuels such as $\mathrm{H}_{2}$-rich and CO-rich syngas. The fundamental issue with syngas combustion is associated with the significant variation in their fuel compositions that changes the combustion characteristics such as flame speed, heat release ratio, local fuel consumption rate and flame instability mechanisms. The responses of swirling flames to these changes are not well characterised or understood. Because of the presence of high hydrogen concentration in a syngas mixture the combustion process of swirl stabilised system could develop into an undesirable flame flashback phenomenon, in which the flame propagates into the burner. The hydrogen-rich swirl flame with high diffusivity can travel upstream and even attach to the wall of the combustor. In general, many existing 
combustors which are currently in use for traditional hydrocarbon combustion may need substantial improvements for the burning of syngas. Furthermore, accurate prediction of the scalar and velocity fields of $\mathrm{H}_{2}$-rich syngas combustion processes in swirl stabilised combustion system is a challenging task in that it requires the solution of a three-dimensional, highly unsteady turbulent reacting flow. As such, the present work investigates the flame characteristics of swirl stabilised nonpremixed $\mathrm{H}_{2} / \mathrm{CO}$ syngas flames using large eddy simulations. In previous studies, we have focused on direct numerical simulation (DNS) of hydrogen [26] and syngas combustion [27] for low Reynolds number impinging jet flames and LES of syngas combustion for high Reynolds number turbulent jet flames [28]. The present work is a continuation of our previous investigations more towards fuel variability and flame dynamics of practical engineering application with the ultimate aim of providing valuable insights on future clean combustion applications. The laboratory scale confined combustion configuration is the TECFLAM swirl burner which has been widely investigated for swirl stabilised natural gas combustion [29-30]. The objective of the research was to analyse the important physics of the effects of fuel variability on the flame characteristics of syngas combustion. The structure of the paper is as follows. Section 2 describes details about the confined simulated swirl burner. Computational details of LES solver and numerical test cases are presented in section 3. Results of the simulations are discussed in section 4. Finally conclusions are summarised in section 5 .

\section{Simulated Swirl Burner}

The computational domain (filtered axial velocity) of the TECFLAM confined swirl burner is shown in Figure 1, which has been used for both nonpremixed and premixed natural gas combustion. Extensive details have been reported in the literature for a range of TECFLAM 
swirling flames including laser Raman measurements and numerical calculations [29-30]. The most commonly used parameter for the characterisation of swirling flows is the swirl number. To investigate the swirl effects, the swirl velocity is introduced into the annular jet at the exit, with the swirl number defined as the ratio between the axial flux of the swirl momentum, $G_{\phi}\left(\mathrm{kgm}^{2} \mathrm{~s}^{-2}\right)$, to the axial flux of the axial momentum $G_{x}\left(\mathrm{kgm}^{2} \mathrm{~s}^{-2}\right)$ multiplied by a characteristic length $R(\mathrm{~m})$. Here we take the radius of the swirl annulus as the characteristic radius. The swirl number is given by

$$
S=\frac{G_{\phi}}{R G_{x}}=\frac{\int_{0}^{R} U W r^{2} d r}{R \int_{0}^{R} U^{2} r d r}
$$

Where $U(\mathrm{~m} / \mathrm{s})$ and $W(\mathrm{~m} / \mathrm{s})$ are the mean axial and tangential velocities at the exit plane of the swirl generator.

The burner has a fuel annulus with an inner diameter of $20 \mathrm{~mm}$ and an outer diameter of 26mm. The primary swirling air stream has an inner diameter of 30mm and an outer diameter of $60 \mathrm{~mm}$. Fuel is supplied at the burner exit with an average axial velocity of $21 \mathrm{~m} / \mathrm{s}$ giving a Reynolds number of 7,900. The air stream mean axial velocity is $23 \mathrm{~m} / \mathrm{s}$ giving a Reynolds number of 42,900. Swirl is introduced aerodynamically by using movable blocks inside the burner with a swirl number of $S=0.9$. The diameter of the combustion chamber used in the experiment is $500 \mathrm{~mm}$ and the walls extend vertically over more than 1 metre. However, for the simulations we have used a distance of $600 \mathrm{~mm}$ vertically to reduce the computational cost for a much larger domain. Since this work focuses on fuel variability and flame characteristics of $\mathrm{H}_{2} / \mathrm{CO}$ syngas mixtures, we considered two syngas mixtures as fuel for our calculations. Considering the fuel compositions, the two flames have been named HCO1 and 
HCO2. The $\mathrm{H}_{2}$-rich flame HCO1 has a fuel mixture of $70 \%$ of $\mathrm{H}_{2}$ and $30 \%$ COby volume. In contrast, CO-rich flame $\mathrm{HCO} 2$ has a fuel mixture of $30 \%$ of $\mathrm{H}_{2}$ and $70 \%$ COagain by volume.

\section{LES Solver and Computational Cases}

The three-dimensional LES code PUFFIN solves the Favre filtered continuity equation, Navier-Stokes momentum equations, the transport equations of mixture fraction for an incompressible reacting gas mixture. The LES code has been used for the investigations of turbulent non-premixed hydrogen-enriched syngas jet flames [28], unconfined swirling flames including validation purposes, instability analysis and intermittency calculations [3133].

The Favre filtered momentum and mixture fraction equations have been closed using the Smagorinsky eddy viscosity model [34] with localised dynamic procedure of Piomelli and Liu [35]. The flame chemistry used in the LES is steady laminar flamelet model [36] which assumes that the balance between reaction and the laminar diffusion in the flame structure is in steady state. The laminar flamelets have been generated using the Flamemaster code [37] which employed detailed GRI 2.11 chemistry mechanism [38]. An assumed probability density function (PDF) for the mixture fraction is chosen as a means of modelling the subgrid scale mixing with beta $(\beta)$ PDF used for the mixture fraction.

The code solves the governing equations by means of pressure based finite volume method on a Cartesian coordinate system. Second order central differences (CDS) are used for the spatial discretisation of all terms in both the momentum equation and the pressure correction equation. The diffusion terms of the mixture fraction transport equation are also discretised 
using the second order CDS while the convection terms are discretised using the "Simple High Accuracy Resolution Program” (SHARP) [39]. The time integration of the mixture fraction is performed using the Crank Nicolson scheme while the time integration of the momentum equations are integrated in time using a second order hybrid scheme. Advection terms are calculated explicitly using second order Adams-Bashforth while diffusion terms are calculated implicitly using second order Adams-Moulton to yield an approximate solution for the velocity field and finally the mass conservation is enforced through a pressure correction step. The systems of algebraic equations resulting from the numerical discretisation are solved using the Bi-Conjugate Gradient Stabilized (BiCGStab) method with a Modified Strongly Implicit (MSI) preconditioner. Comprehensive details on governing equations, flame chemistry and numerical discretisation methods used for this study have been reported previously [28].

LES calculations for flames $\mathrm{H}_{2}$-rich and CO-lean flame $\mathrm{HCO} 1\left(70 \% \mathrm{H}_{2}\right.$ and $30 \%$ COby volume) and, $\mathrm{H}_{2}$-lean and CO-rich flame $\mathrm{HCO} 2\left(30 \% \mathrm{H}_{2}\right.$ and $70 \%$ COby volume ) were performed on non-uniform Cartesian grids with dimensions of 500mm radially ( $\mathrm{y}$ and $\mathrm{z}$ directions) and $600 \mathrm{~mm}$ axially (x direction) by employing $200 \times 150 \times 150$ grid points in $\mathrm{x}, \mathrm{y}$ and $\mathrm{z}$ directions (4.5 million grid nodes) (Fig.1). The mean axial velocity distribution for the fuel inlet and mean axial and swirling velocity distributions for the primary air annulus are specified using power law profiles. Turbulent velocity fluctuations are generated from a Gaussian random number generator, which are then added to the mean velocity profiles. The inlet boundary condition for the mixture fraction is specified using a top hat profile. A no-slip wall boundary condition is applied at the solid walls. A convective outlet boundary condition and a zero normal gradient boundary condition are used at the outflow plane for velocity and mixture fraction respectively. All LES calculations have been performed for approximately 
10 flow passes instantaneously before collected data for time-averaged calculation for approximately another 10 flow passes based on the inlet axial velocity.

\section{Results and Discussion}

In the present section results from LES of two $\mathrm{H}_{2} / \mathrm{CO}$ based syngas swirling flame characteristics are presented. The considered flames are $\mathrm{H}_{2}$-rich and CO-lean flame HCO1 and, $\mathrm{H}_{2}$-lean and CO-rich flame $\mathrm{HCO} 2$ and with high swirl number 0.9. The intention is to study the influence of $\mathrm{H}_{2}$ and $\mathrm{CO}$ on flame characteristics of turbulent non-premixed $\mathrm{H}_{2} / \mathrm{CO}$ syngas flames in the presence of complex recirculation and vortex breakdown flow features. The first section describes the instantaneous properties and second section describes the time-averaged statistics.

\subsection{Unsteady Flame Analysis}

To address the feasibility of syngas for fuel flexible swirl stabilised combustion, one must be able to accurately predict the flame behaviour such as flow regimes and stability limits which affect the chemical kinetics, species transport properties and flame speeds. Therefore, the nature of instantaneous quantities such as axial and swirl (flow characteristics) velocities and density, mixture fraction and temperature (scalar characteristics) are discussed in this section.

Swirling flows can exhibit a very large range of topologies, depending mainly on the swirl number [12]. Swirl of sufficient strength produces a large adverse pressure gradient in the direction of the flow, which promotes vortex breakdown, a phenomena that manifests itself as an abrupt change in the core of the slender vortex, and usually develops downstream into a recirculation bubble and serves as an aerodynamic flame holder. In Fig. 2, instantaneous 
filtered axial and swirl velocity of flames $\mathrm{HCO} 1$ and $\mathrm{HCO} 2$ at $\mathrm{t}=0.28 \mathrm{~s}$ (approximately 10 flow passes) are shown by the two-dimensional contour plots. The flow-field of the $\mathrm{H}_{2}$-rich flame $\mathrm{HCO} 1$ and $\mathrm{CO}$-rich flame $\mathrm{HCO} 2$ demonstrate two flow structures: shear layers originating from the outer edge of the inlet annulus (defined as zone A) and vortex breakdown induced center recirculation zone (defined as zone B). Two important trends have been observed from Fig. 2. (1) the distribution of the axial velocity of $\mathrm{H}_{2}$-rich flame HCO1 spread more radially than CO-rich flame $\mathrm{HCO} 2$ in zone A, indicating that the axial velocity distribution in the shear layers originating from the outer edge of the inlet annulus possibly linked with the diffusivity level of $\mathrm{H}_{2}$ fuel and thus its chemical and transport properties; and (2) the formation of the VB displays a larger and wider bubble for $\mathrm{H}_{2}$-rich flame $\mathrm{HCO} 1$ compared to CO-rich flame HCO2 in zone B. This could be because of the faster fuel consumption linked with the diffusivity factor depending on the syngas fuel mixture composition especially the large amount of hydrogen in flame HCO1. The snapshots of the velocity components indicate that the $\mathrm{H}_{2}$ percentage in the fuel mixture strongly affects the flow and thus combustion dynamics when burning high hydrogen content fuels in combustion systems.

As the flow expands with a different pattern distribution from the nozzle and evolves downstream, the scalar distributions are expected to display different structures due to fuel variability between two flames. To identify potential regions for active scalar mixing, results are now focused on unsteady scalar distributions. Fig.3 shows instantaneous results for three important scalar variables, density, mixture fraction and temperature. The density is an important parameter, because it contains fundamental information regarding reactivity and diffusivity of a combustible mixture that can be used to gain insight into fundamental flame physics with respect to fuel variability. Despite using similar inlet velocity flow conditions 
including equal swirl number, there is a substantial difference for the scalar fields between the $\mathrm{H}_{2}$-rich flame $\mathrm{HCO} 1$ and $\mathrm{CO}$-rich flame $\mathrm{HCO} 2$ in the recirculation and VB regions. For example, as seen in Fig. 3 (a1, b1) the density distribution of flame HCO1 exhibits a much larger portion of low density values in zones A and B compared to the density distribution of flame HCO2. Similar behaviour is apparent for mixture fraction and temperature distributions. This might be because of the changes of diffusivity level and variations of transport properties. The amount of hydrogen in the fuel and the variations of transport properties associated with fuel variability can change the density, mixing rate and accordingly the chemical reaction and temperature distribution. To further analyse the unsteady flame temperature with respect to fuel variability, three-dimensional LES of flame structures at different iso-surface values are represented in Fig. 4. The topology of the 3D flames exhibit different structures for $\mathrm{H}_{2}$-rich flame $\mathrm{HCO} 1$ and $\mathrm{CO}$-rich flame HCO2. The 3D temperature of flame HCO1 displays a larger spread compared to flame HCO2. This is not surprising, as a large radially expanding VB bubble is evident, which affects the 3D temperature distribution.

\subsection{Averaged Field}

In conjunction with the unsteady flame analysis, steady time averaged quantities are also used to further clarify major findings with respect to fuel variability. To illustrate this, the distributions of time-averaged mean variables are now presented. A contour plot of timeaveraged mean axial velocity for flames HCO1 and HCO2 is shown in Fig. 5. Similar to the transient behaviour, the two flames display differences in both zone A and B. Particularly, the formation of VB bubble for $\mathrm{H}_{2}$-rich flame $\mathrm{HCO} 1$ shows a larger expansion compared to the 
VB bubble for the CO-rich flame HCO12, which indicates the effects of fuel variability on steady flow field.

Figs. 6 and 7 show radial profiles of time-averaged mean axial and swirl velocities at upstream and downstream axial locations. To validate the LES based numerical results of HCO1 and HCO2 syngas flames, here we consider the experimental data of TECFLAM natural gas swirl stabilised flame [29, 30]. Despite quantitative differences occur due to fuel variability the comparison of simulation results (HCO1 and HCO2 flames) and experimental data (natural gas flame) show consistency which highlight the accuracy of the flow features of numerically simulated syngas flames. Here, LES appears to be successful in reproducing all the flow features seen in the experiments. It should be noted that the results also show more strong VB bubble for natural gas flame compared to simulated syngas flames.

It is evident that the radial profiles of time-averaged mean axial and swirl velocities display a similar behaviour in the near nozzle region for $\mathrm{H}_{2}$-rich flame HCO1 and CO-rich flame HCO2, but deviate significantly in zone A and zone B in VB region. Despite showing a similar shape distribution, it is clear that the mean axial velocity profile of CO-rich flame HCO2 shifts towards one side compared to the $\mathrm{H}_{2}$-rich flame HCO1. Therefore the transport mechanism caused by the diffusivity level associated with fuel composition affects the mean flow-field too, similar to that observed for the instantaneous flow structure. The deviation of mean axial velocity for HCO1 and HCO2 starts to appear at the end of zone A (in Fig. 2) and continues to be apparent in zone B, where the swirl induced VB occurs further downstream. Subsequently, similar behaviour is apparent in Fig.7 in which mean swirl velocity for the CO-rich flame HCO2 shows slightly higher peak values at the downstream VB region compared to its values for the $\mathrm{H}_{2}$-rich flame HCO1. Both mean axial and swirling velocities 
suggest that the fuel variability from $\mathrm{H}_{2}$-rich to CO-rich and particularly the $\mathrm{H}_{2}$ percentage of the fuel composition play an important fundamental role and largely affects the formation of flow structures in swirling flames.

We now examine the time-averaged scalar quantities. Figs. 8 and 9 display the comparisons of time-averaged mean mixture fraction and mixture fraction variance between the two flames. Again, a most possible interpretation of the deviation of the mixture fraction and its variance between two flames is the diffusivity level. As seen in both Fig. 8 and 9, adding more $\mathrm{CO}$ to $\mathrm{H}_{2}$ tends to generate higher peak values for the mixture fraction and its variance (flame HCO2) compared to its behaviour in high $\mathrm{H}_{2}$ content fuel mixture (flame HCO1). Since flame temperature is dependent on the mixture fraction distribution through the laminar flamelet model, results for the flame temperature and combustion by-products are expected to produce similar trends. The role of the alignment between fuel composition and diffusivity level particularly for the $\mathrm{H}_{2}$ enriched fuel is of much significance. To provide a comprehensive analysis for the flame temperature, Fig. 10 shows the radial profiles of mean temperature values at different downstream axial locations. The peak values of the temperature are seen in the shear layer regions. Both the $\mathrm{H}_{2}$-rich flame $\mathrm{HCO} 1$ and the CO-rich flame HCO2 generate high peak temperature values in the near field region. It is important to note that the $\mathrm{H}_{2}$-rich flame $\mathrm{HCO} 1$ has the highest peak temperature in the intermediate region (zone A) while the CO-rich flame $\mathrm{HCO} 2$ has higher peak values in the downstream VB region (zone B). Combustion occurs in the shear layer as the fuel is advected into the air stream and its transport to the inner region is limited by the inner diluent. The outer diluent, on the other hand, which is between fuel and air streams, avoids early mixing and keeps the flame away from the injection plane. Although the results are obtained using 
GRI 2Mech 2.11, there is further interest in identifying more appropriate chemical mechanisms to model syngas mixtures as functions of fuel composition, strain rate, pressure and temperature. In the future we intend to employ other chemical mechanisms such as the Davis $\mathrm{H}_{2} / \mathrm{CO}$ mechanism [40] and reduced mechanism for $\mathrm{H}_{2} / \mathrm{CO}$ syngas based swirl stabilised combustion applications.

Fig. 11 shows the comparison of product mass fraction of water vapour between HCO1 and HCO2 at various axial locations. Comparisons between two flames reveal that the considerably high peak values exhibited by the $\mathrm{H}_{2}$-rich flame compared to CO-rich flame are due mainly to the higher percentage of $\mathrm{H}_{2}$ in the HCO1 fuel mixture. The shape distribution of mass fraction of $\mathrm{H}_{2} \mathrm{O}$ follows the temperature distribution with peak values appearing to be larger in the intermediate region (zone A) and then similar to each other in the furthest downstream VB region (zone B) for the two flames. The product mass fraction of $\mathrm{CO}_{2}$ is shown in Fig. 12. Again, the mass fraction of $\mathrm{CO}_{2}$ follows a distribution similar to the temperature and the mass fraction of $\mathrm{H}_{2} \mathrm{O}$, but peak values occur for the $\mathrm{CO}$-rich $\mathrm{HCO} 2$. We note that there is very high peak values exhibited for the CO-rich flame HCO2 compared to much lower peak values for the $\mathrm{H}_{2}$-rich flame $\mathrm{HCO} 1$.

Results described in this work are more fundamental in some respects, since these results for the fuel variability and flame characteristics are obtained for an academically established experimental burner [29-30]. It is important to note that present calculations were performed considering unity Lewis number ( $L e \approx 1$ ), which prevents the preferential (or differential) diffusion effects. Hence the influence of thermo-diffusive effects is neglected. However, inclusion of non-unity Lewis number effects to account for preferential diffusion is likely to be an important step for the modelling high hydrogen content fuels and therefore deserve 
more detailed investigation [41]. Nevertheless, interesting and useful insights directly relevant to practical designs can be filtered from the current data. Particularly, the flow-field

evolution, flame temperature and combustion products relevant to $\mathrm{H}_{2}$-rich and CO-lean to $\mathrm{H}_{2}$-lean and CO-rich fuel mixtures would be an issue of utmost importance in future clean combustion development for practical engineering application. Further investigations on critical parameters such as flame length, combustor exit temperature pattern factor, mixing rates and $\mathrm{NO}_{\mathrm{x}}$ emissions which provide direct design guidelines for future syngas based combustors would be of great interest.

\section{Conclusions}

We compared the numerical results of two non-premixed $\mathrm{H}_{2} / \mathrm{CO}$ swirl stabilised syngas flames using large eddy simulation and the laminar flamelet combustion model. Results were analysed under two sections: unsteady evolution and time-averaged fields. The discussion indicates strong effects of the fuel variability on the formation of flame structure for high swirl non-premixed flames. The high diffusivity of hydrogen tends to form highly unsteady flame characteristics with much lower density distributions particularly in fuel rich regions and thus generate a larger $\mathrm{VB}$ bubble in the presence of swirl compared to the $\mathrm{H}_{2}$-lean flame. Accordingly, we postulate that turbulent syngas swirling flame is not only governed by the inlet flow conditions but also by the fuel mixture which plays an important role particularly for high hydrogen content fuels, thereby inducing different diffusivity levels.

All of these findings have considerable implications for fuel variability and flame characteristics of swirl stabilised turbulent non-premixed combustion. Further examination of the key issues such as fuel variability, combustion instability and emissions particularly in 
high pressure swirl stabilised combustion systems would provide great interest for future studies. For example, an analysis of the importance of the most significant instability driven mechanisms in gas turbine type combustion configurations such as flame-vortex interactions, fuel/air ratio and spray-flow interactions for high hydrogen content fuel could be assessed by a large parametric study spanning different modes of syngas mixtures. 


\section{References}

[1] Miller B. Clean coal engineering technology. Butterworth-Heinemann, Burlington, MA, USA, 2011.

[2] Lieuwen T, Yang V, Yetter R. Synthesis gas combustion: Fundamentals and applications, CRC Press Taylor and Francis Group, FL, USA, 2010.

[3] International Energy Agency (IEA). Greenhouse gas and R\&D programme (GHG). Coproduction of hydrogen and electricity by coal gasification with $\mathrm{CO}_{2}$ capture. Report 13/2007; 2007

[4] Chiesa P, Consonni S, Kreutz T, Williams R. Co-production of hydrogen, electricity and $\mathrm{CO}_{2}$ from coal with commercially ready technology. Part A: performance and emissions. Int. J. Hydrogen Energy 2005; 30: 747-767.

[5] Kunze C, Spliethoff H. Modelling of an IGCC plant with carbon capture for 2020. Fuel Proc. Tech. 2010; 91: 934-941.

[6] Cormos CC. Evaluation of energy integration aspects for IGCC-based hydrogen and electricity co-production with carbon capture and storage. Int. J. Hydrogen Energy 2010; 35: 7485-7497.

[7] Lieuwen T, McDonell V, Santavicca D, Sattelmayer T. Burner development and operability issues associated with steady flowing syngas fired combustors. Combust. Sci. Tech. 2008; 180: 1169-1192.

[8] Dam B, Corona G, Hayder M, Choudhuri A. Effects of syngas composition on combustion induced vortex breakdown (CIVB) flashback in a swirl stabilised combustor. Fuel 2011; 90: 3274-3284. 
[9] Syred N, Beer JM. Combustion in swirling flows: a review. Combust. Flame 1974; 23 : 143-201.

[10] Gupta AK, Lilly DG, Syred N. Swirl flows. Abacus Press, Kent, England, 1984.

[11] Escudier M. Vortex breakdown: observations and explanations. Prog. Aero. Sci. 1988; 25: 189-229.

[12] Lucca-Negro O, O’Doherty TO. Vortex breakdown: A review. Prog. Energy. Combust. Sci. 2001; 27: 431-481.

[13] Syred N. A review of oscillation mechanisms and the role of the precessing vortex core (PVC) in swirl combustion systems. Prog. Energy. Combust. Sci. 2006; 32: 93-161.

[14] Froud D, O’Doherty T, Syred N. Phase averaging of the precessing vortex core in a swirl burner under piloted and premixed combustion conditions. Combust. Flame 1995; 100: 407417.

[15] Westbrook C, Mizobuchi Y, Poinsot TJ, Smith PJ, Warnatz J. Computational combustion. Proc. Combust. Inst. 2005; 30 (1): 125-157.

[16] Kempf A, Malalasekera W, Ranga Dinesh KKJ, Stein O. Large eddy simulation with swirling non-premixed flames with flamelet model: A comparison of numerical methods. Flow Turb. Combust. 2008; 81: 523-561.

[17] Oefelein JC. Large eddy simulation of turbulent combustion processes in propulsion and power systems. Prog. Aero. Sciences 2006; 42: 2-37.

[18] Patel N, Menon S. Simulation of spray-turbulence-chemistry interactions in a lean direct injection combustor. Combust. Flame 2008; 153: 228-257. 
[19] Roux A, Gicquel LYM, Sommerer Y, Poinsot TJ. Large eddy simulation of mean and oscillating flow in a side dump ramjet combustor. Combust. Flame 2008; 152: 154-176.

[20] Pitsch H. Large eddy simulation of turbulent combustion. Ann. Rev. Fluid Mech. 2006; 38: 453-482.

[21] Di Mare F, Jones W, Menzies K. Large eddy simulation of a model gas turbine combustor. Combust. Flame 2004; 137(3): 278-294.

[22] Grinstein FF, Fureby C. LES studies of the flow in a swirl gas combustor. Proc. Combust. Inst. 2005; 30: 1791-1798.

[23] Mahesh K, Constantinescu G, Apte S, Iaccarineo G, Ham F, Moin P. Large eddy simulation of turbulent flow in complex geometries. ASME J. App. Mech. 2006; 73: 374381.

[24] Boudier GL, Gicquel YM, Poinsot TJ. Effects of mesh resolution on large eddy simulations of reacting flows in complex geometry combustors. Combust. Flame 2008; 155: 196-214.

[25] Bioleau M, Staffelbach G, Cuenot B, Poinsot T, Berat C. LES of an ignition sequence in gas turbine engine. Combust. Flame 2008; 154: 2-22.

[26] Ranga Dinesh KKJ, Jiang X, van Oijen JA. Numerical simulation of hydrogen impinging jet flame using flamelet generated manifold reduction. Int. J. Hydrogen Energy 2012; 37: 4502-4515.

[27] Ranga Dinesh KKJ, Jiang X, van Oijen JA, Bastiaans RJM, de Goey LPH. Influence of fuel variability on the characteristics of impinging non-premixed syngas burning. Proc. Combust Inst. 2013; 34: 3219-3229. 
[28] Ranga Dinesh KKJ, Jiang X, Kirkpatrick MP, Malalasekera W. Combustion characteristics of hydrogen/nitrogen and hydrogen/carbon monoxide syngas nonpremixed flames. Int. J. Hydrogen Energy 2012; 37: 16186-16200.

[29] Meier W, Keck O, Noll B, Kunz O Stricker W. Investigations in the TECFLAM swirling diffusion flame: Laser Raman measurements and CFD calculations. Appl. Phys. B 2000; 71: 725-731.

[30] Keck O, Meier W, Stricker W, Aigner M. Establishment of a confined swirling natural gas/air flame as a standard flame: temperature and species distribution from laser Raman measurements, Combust. Sci. Tech. 2002; 174 (8): 117-151.

[31] Ranga Dinesh KKJ, Jenkins KW, Kirkpatrick MP, Malalasekera W. Identification and analysis of instability in non-premixed swirling flames using LES. Combust Theory Model 2009; 13 (6): 947-971.

[32] Ranga Dinesh KKJ, Jenkins KW, Kirkpatrick MP, Malalasekera W. Modelling of instabilities in swirling flames. J. Fuel 2010; 89:10-18.

[33] Ranga Dinesh KKJ, Jenkins KW, Kirkpatrick, MP, Malalasekera W. Effects of swirl on intermittency characteristics in non-premixed flames. Combust Sci Tech 2012; 184: 629-659.

[34] Smagorinsky J. General circulation experiments with the primitive equations, the basic experiment. Mon. Weath. Rev. 1963; 91:99-164.

[35] Piomelli U, Liu J. Large eddy simulation of rotating channel flows using a localized dynamic model. Phys. Fluids 1995; 7:839-848.

[36] Peters N. Laminar diffusion flamelet models in non-premixed turbulent combustion. Prog Energy Combust Sci 1994; 10:319-339. 
[37] Pitsch H. A C++ computer program for 0-D and 1-D laminar flame calculations. RWTH, Aachen, 1998.

[38] Bowman CT, Hanson RK, Davidson DF, Gardiner WC, Lissianki V, Smith GP, Golden DM, Frenklach M, Goldenberg M, GRI 2.11, 2006.

[39] Leonard BP. SHARP simulation of discontinuities in highly convective steady flows. NASA Tech Memo. Vol. 100240, 1987.

[40] Davis SG, Joshi AV, Wang H, Egolfopoulos F. An optimised kinetic model of H2/CO combustion. Proc. Combust. Inst. 2005; 30: 1283-1292.

[41] Ranga Dinesh KKJ, Jiang X, van Oijen JA, Bastiaans RJM, de Goey LPH. Hydrogenenriched nonpremixed jet flames: effects of preferential diffusion. Int. J. Hydrogen Energy 2013; 38: 4848-4863. 


\section{Figure Captions}

Fig.1. Geometry of the swirl burner (generated for the LES instantaneous axial velocity).

Fig.2. Instantaneous filtered (1) axial velocity and (2) swirl velocity of syngas flame (a) HCO1 and (b) HCO2.

Fig.3. Instantaneous filtered (1) density, (2) mixture fraction and (3) temperature of syngas flame (a) HCO1 and (b) HCO2.

Fig.4. Instantaneous three-dimensional iso-surfaces with iso-values (1) 500K, (2) $1000 \mathrm{~K}$, (3) 2000K, of the flame temperature of flames (a) HCO1 and (b) HCO2.

Fig.5. Contour plot of time-averaged mean axial velocity (a) HCO1 and (b) HCO2.

Fig.6. Time-averaged mean axial velocity for flames (a) HCO1 and (b) HCO2. Solid line denotes LES data for flame HCO1 and dashed line denotes LES data for flame HCO2. Symbols denote experimental data for natural gas flame [29, 30].

Fig.7. Time-averaged mean swirling velocity for flames (a) HCO1 and (b) HCO2. Solid line denotes LES data for flame HCO1 and dashed line denotes LES data for flame HCO2. Symbols denote experimental data for natural gas flame [29, 30].

Fig.8. Time-averaged mean mixture fraction for flames (a) HCO1 and (b) HCO2. Solid line denotes LES data for flame HCO1 and dashed line denotes LES data for flame HCO2.

Fig.9. Time-averaged mixture fraction variance for flames (a) HCO1 and (b) HCO2. Solid line denotes LES data for flame HCO1 and dashed line denotes LES data for flame HCO2.

Fig.10. Time-averaged mean temperature for flames (a) HCO1 and (b) HCO2. Solid line denotes LES data for flame HCO1 and dashed line denotes LES data for flame HCO2.

Fig.11. Time-averaged mass fraction of $\mathrm{H}_{2} \mathrm{O}$ for flames (a) HCO1 and (b) HCO2. Solid line denotes LES data for flame HCO1 and dashed line denotes LES data for flame HCO2.

Fig.12. Time-averaged mass fraction of $\mathrm{CO}_{2}$ for flames (a) HCO1 and (b) HCO2. Solid line denotes LES data for flame HCO1 and dashed line denotes LES data for flame HCO2. 


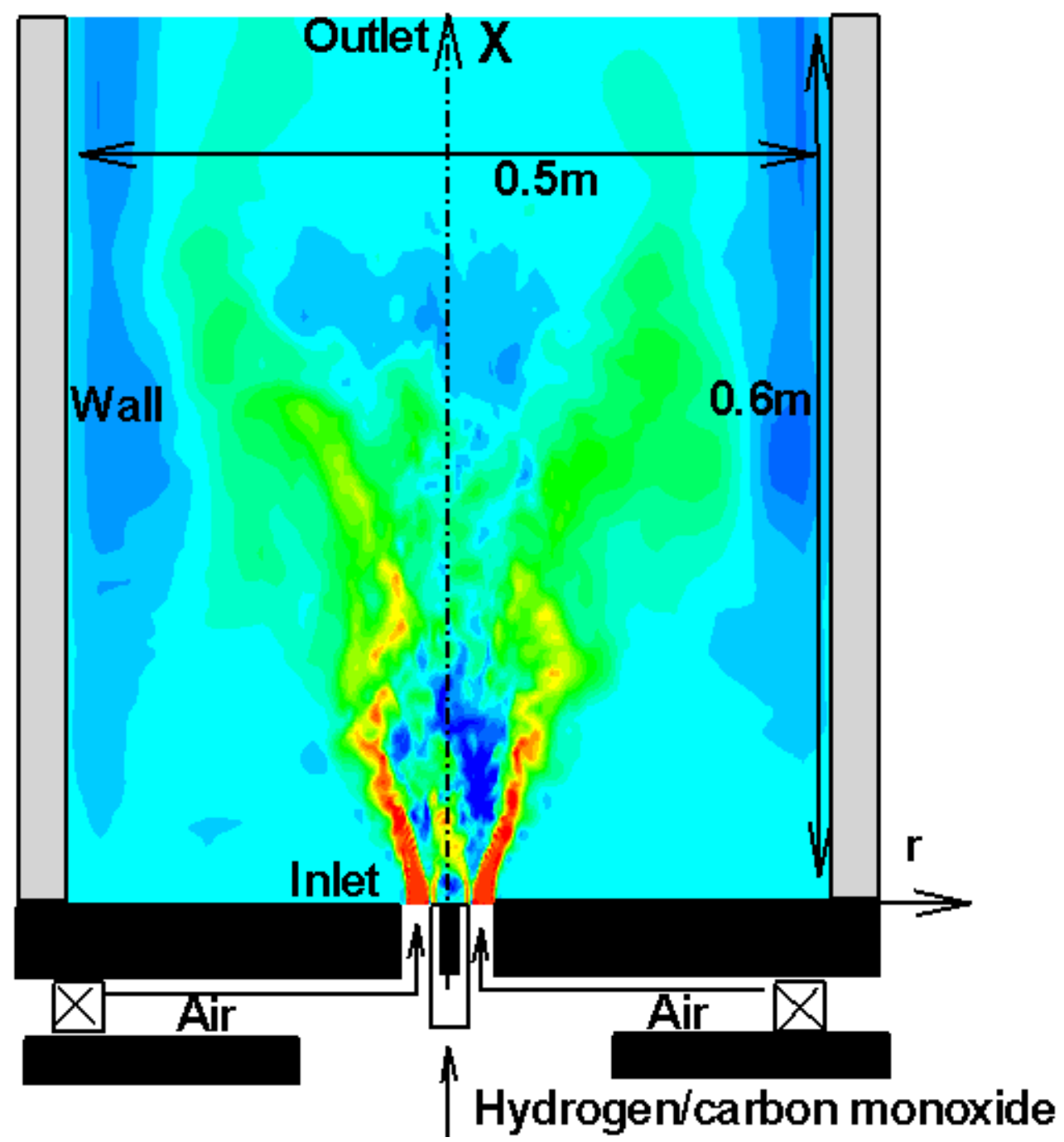

Fig.1. Geometry of the swirl burner (generated for the LES instantaneous axial velocity). 

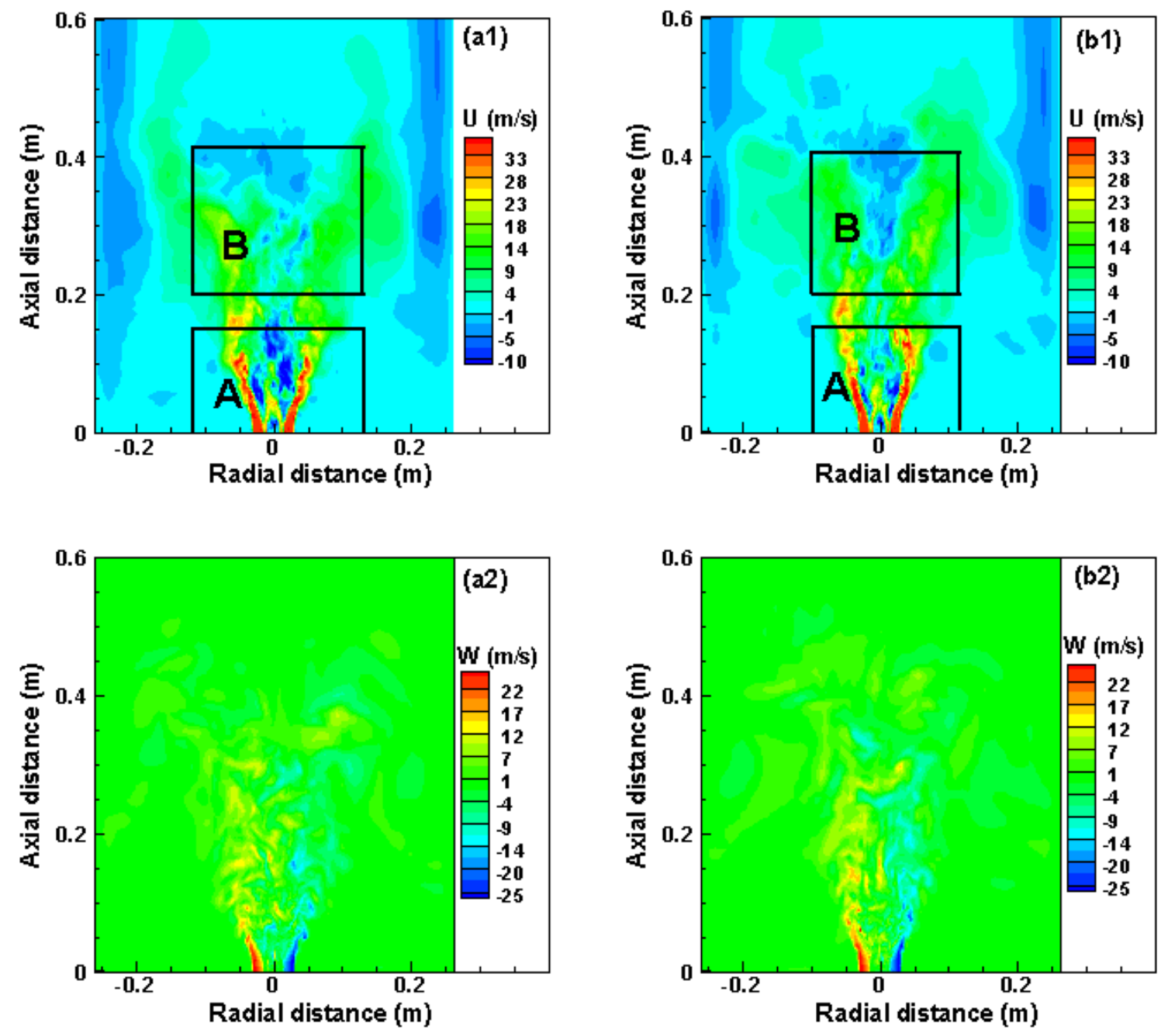

Fig.2. Instantaneous filtered (1) axial velocity and (2) swirl velocity of syngas flame (a) HCO1 and (b) HCO2. 

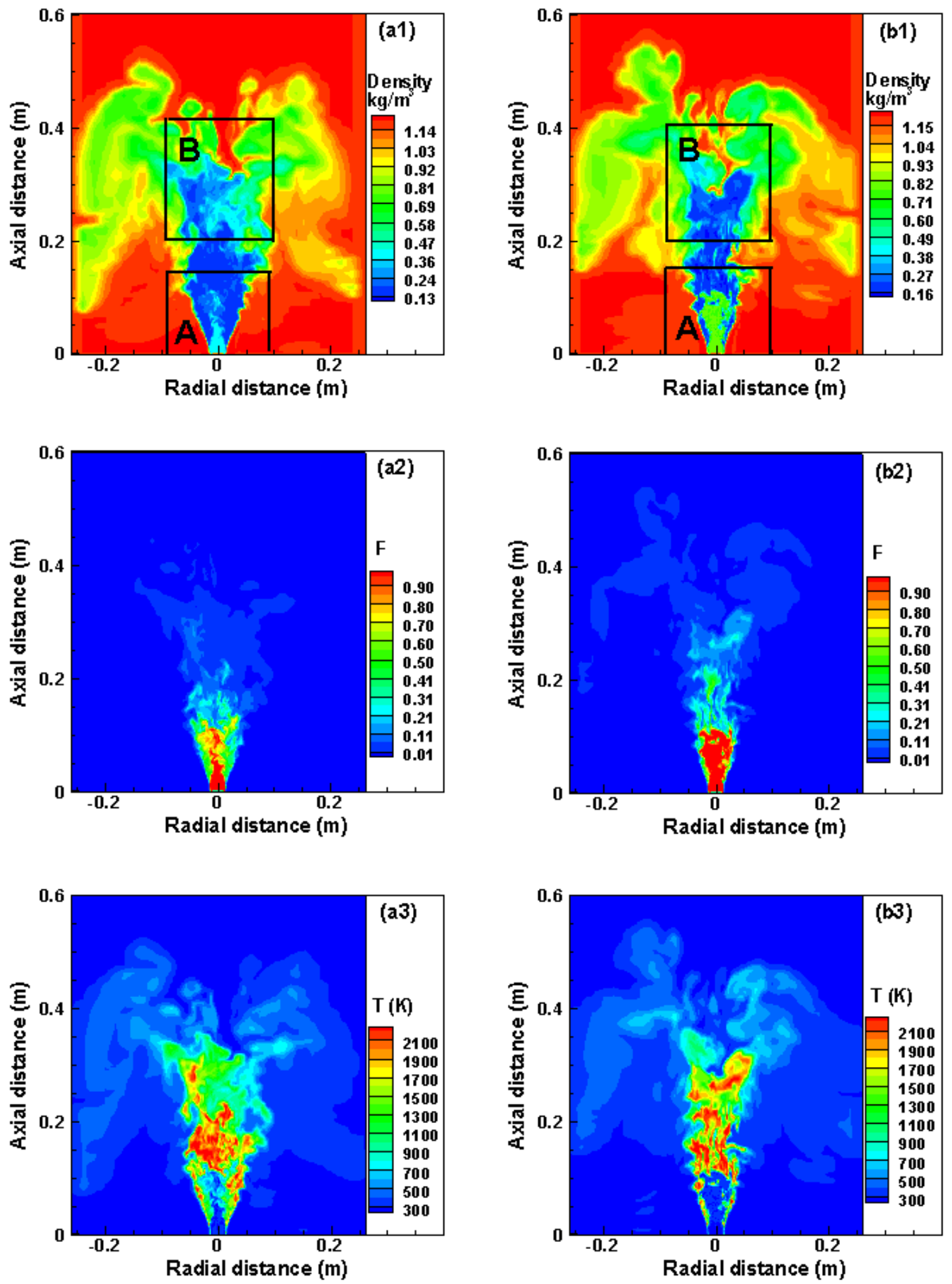

Fig.3. Instantaneous filtered (1) density, (2) mixture fraction and (3) temperature of syngas flame (a) HCO1 and (b) HCO2. 

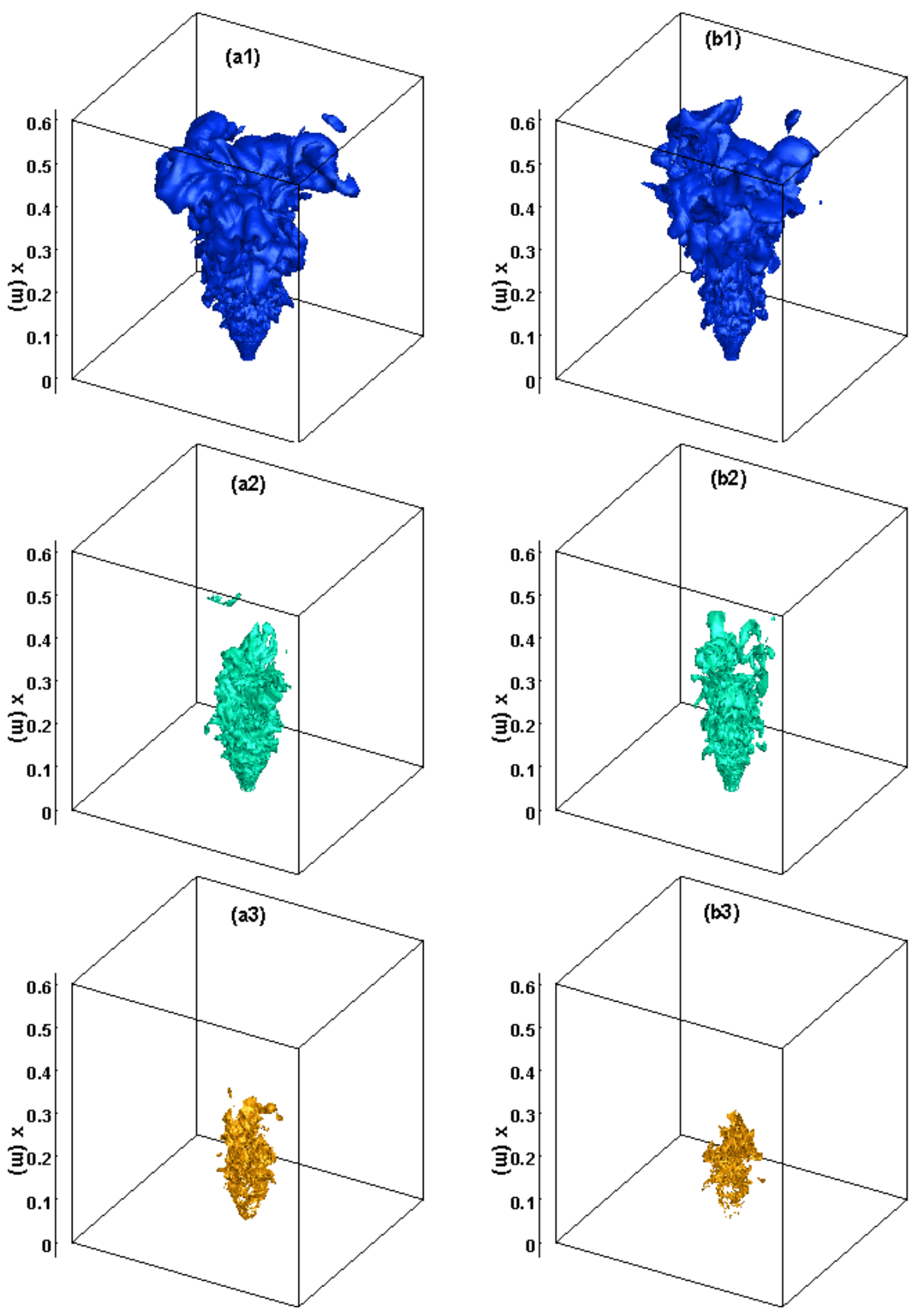

Fig.4. Instantaneous three-dimensional iso-surfaces with iso-values (1) 500K, (2) $1000 \mathrm{~K}$, (3) 2000K, of the flame temperature of flames (a) HCO1 and (b) HCO2. 

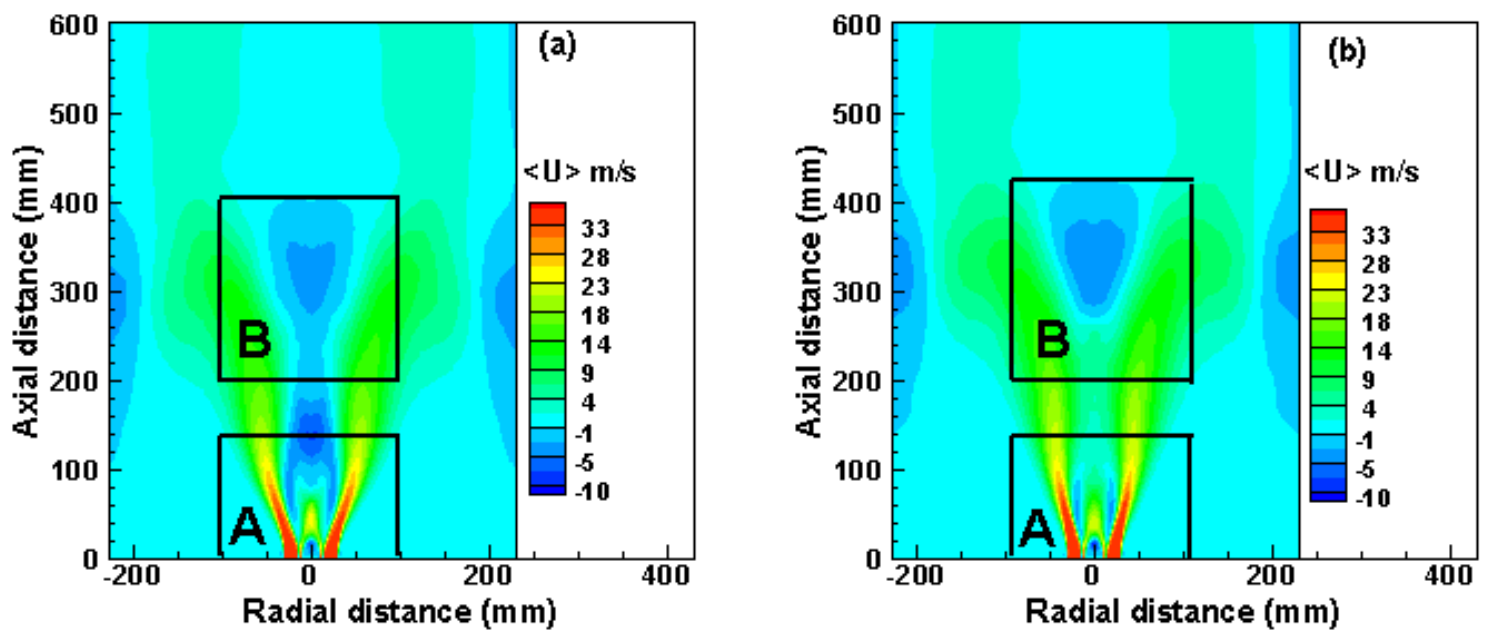

Fig.5. Contour plot of time-averaged mean axial velocity (a) HCO1 and (b) HCO2. 

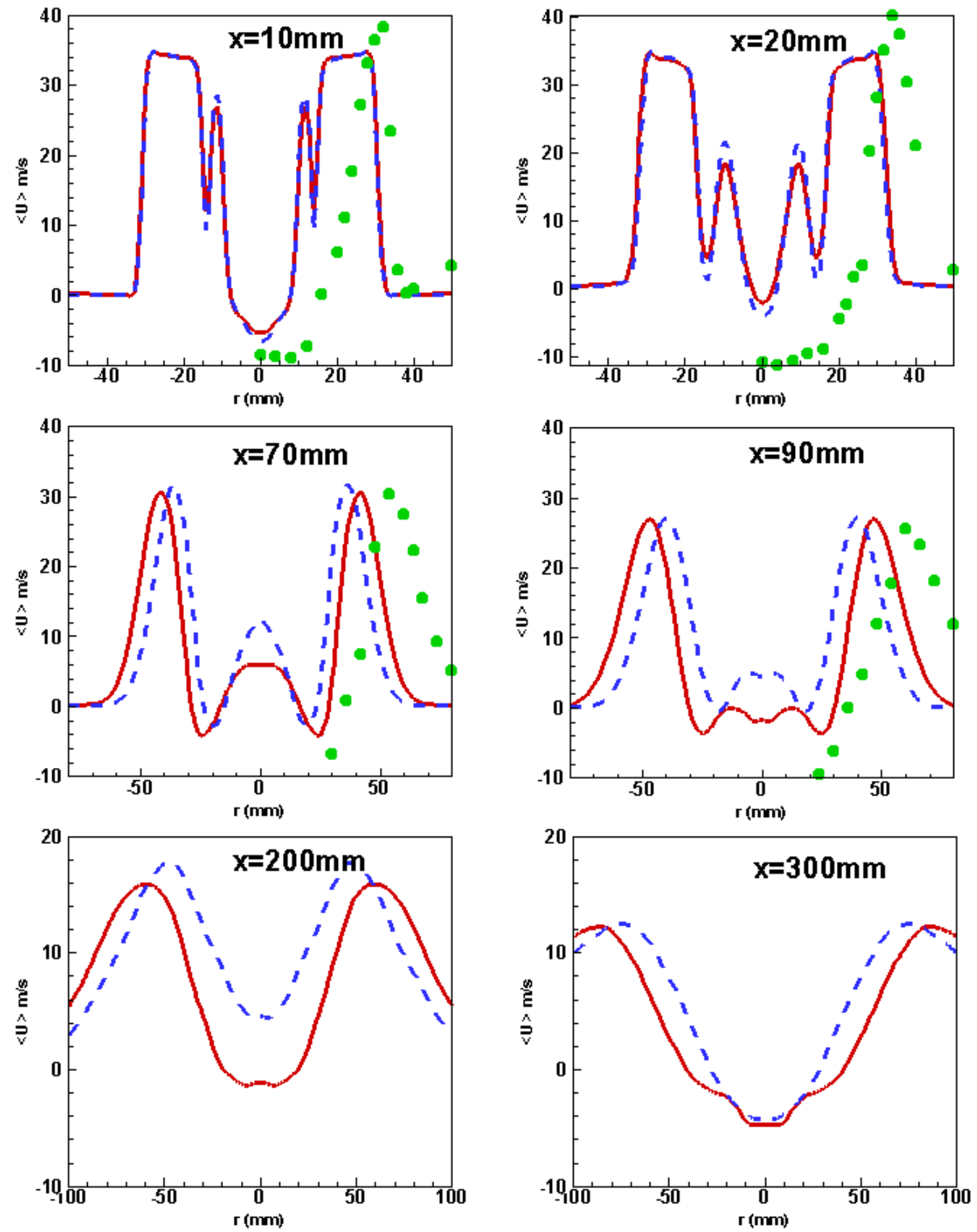

Fig.6. Time-averaged mean axial velocity for flames (a) HCO1 and (b) HCO2. Solid line denotes LES data for flame HCO1 and dashed line denotes LES data for flame HCO2. Symbols denote experimental data for natural gas flame [29, 30]. 

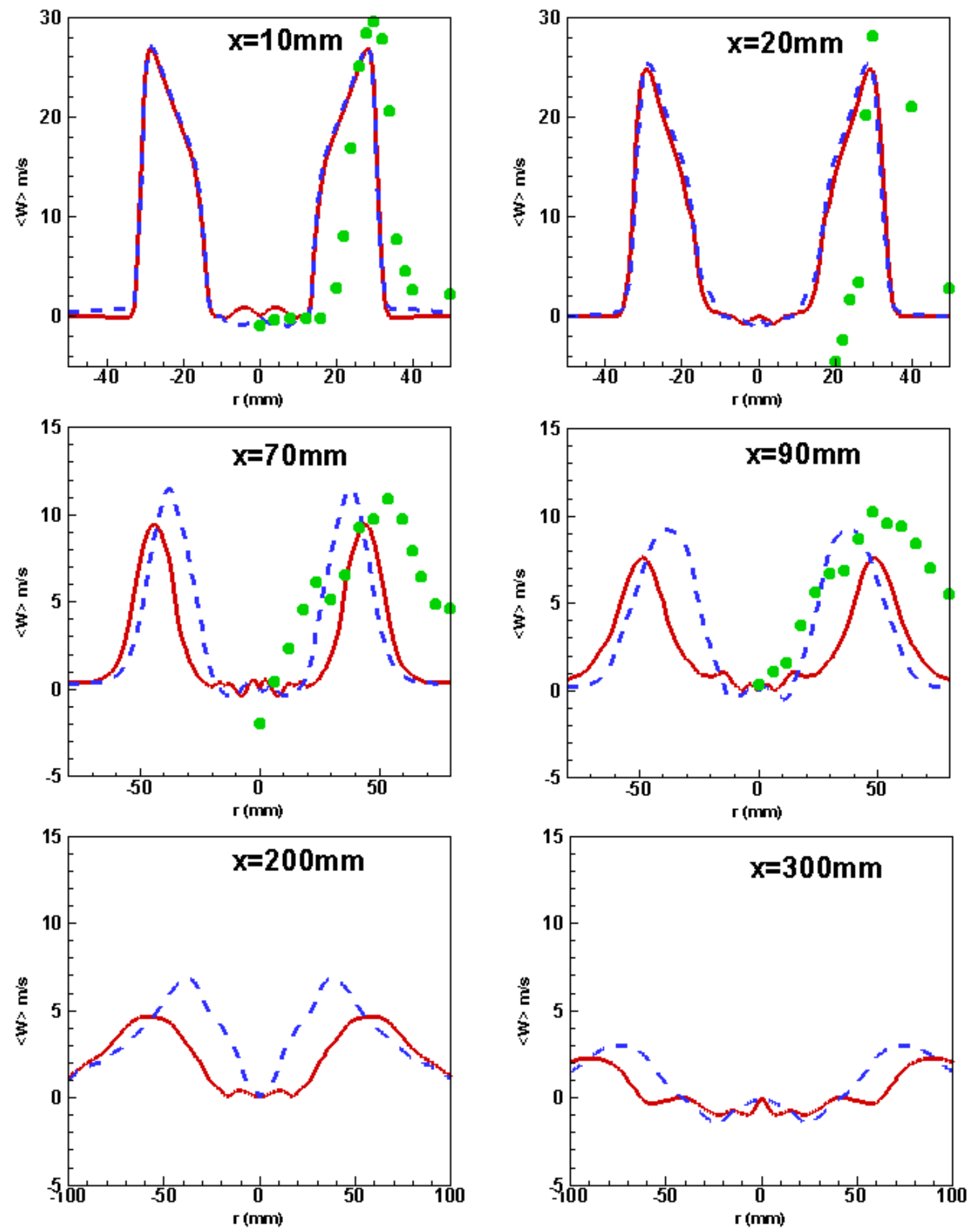

Fig.7. Time-averaged mean swirling velocity for flames (a) HCO1 and (b) HCO2. Solid line denotes LES data for flame HCO1 and dashed line denotes LES data for flame HCO2. Symbols denote experimental data for natural gas flame [29, 30]. 

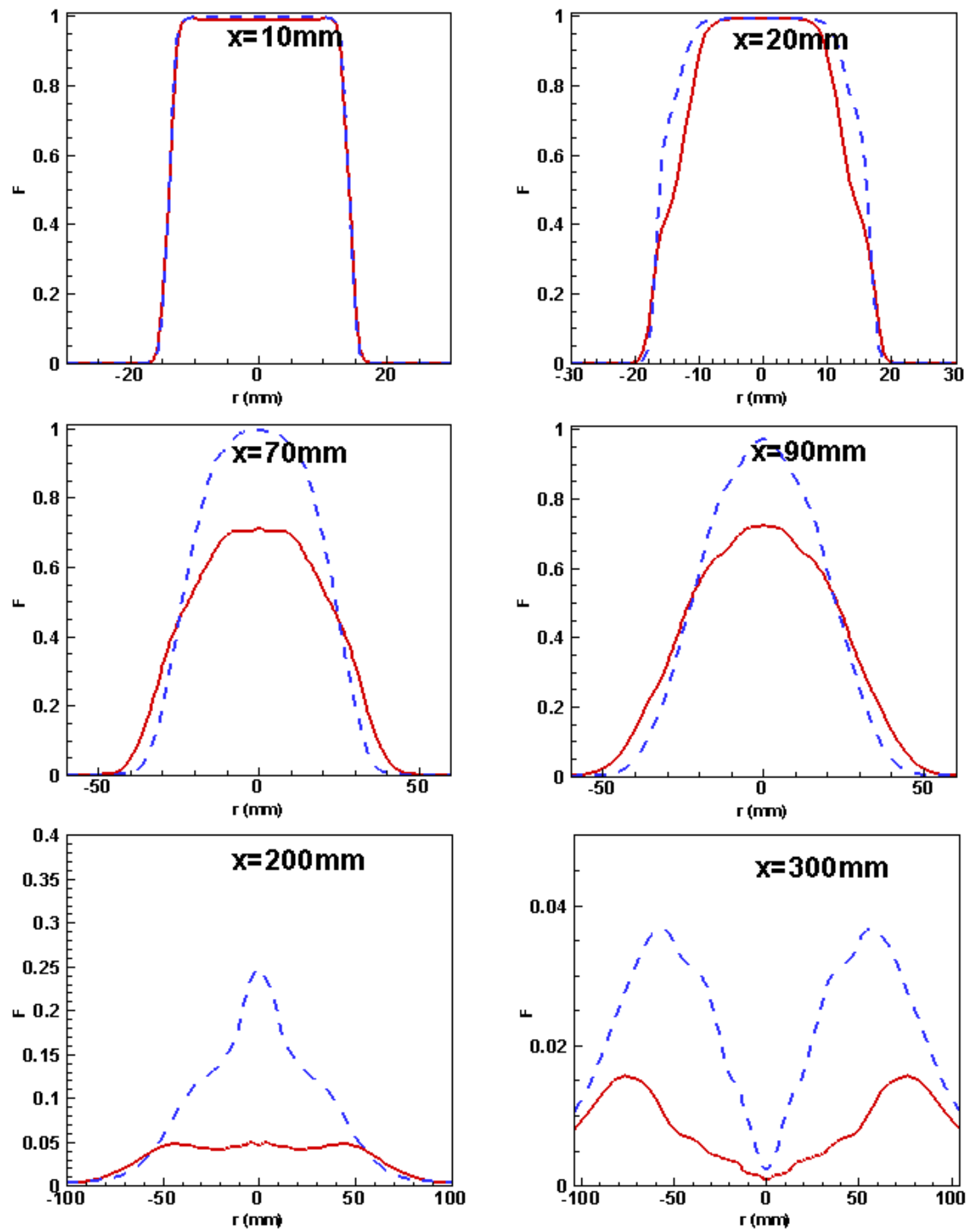

Fig.8. Time-averaged mean mixture fraction for flames (a) HCO1 and (b) HCO2. Solid line denotes LES data for flame HCO1 and dashed line denotes LES data for flame HCO2. 

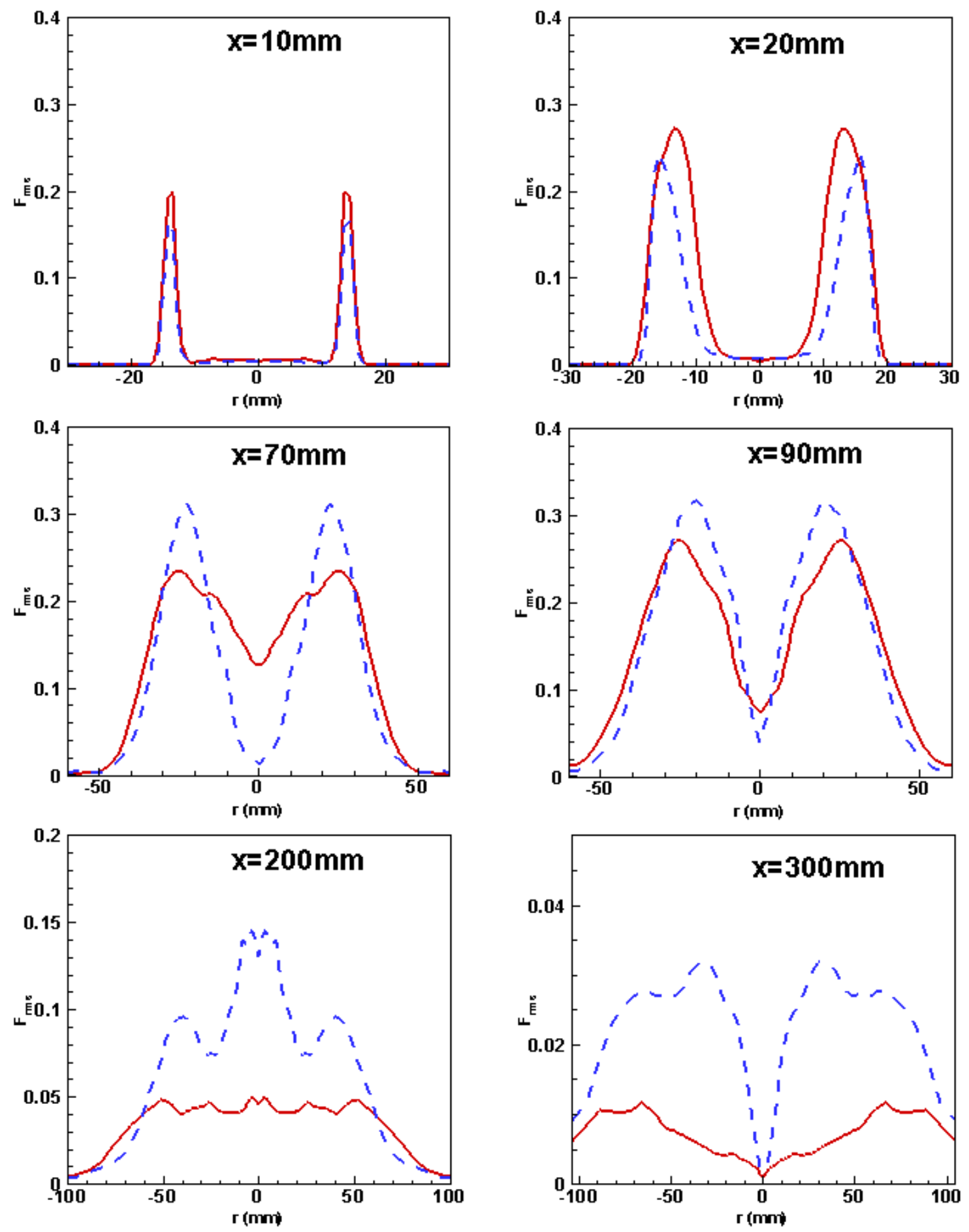

Fig.9. Time-averaged mixture fraction variance for flames (a) HCO1 and (b) HCO2. Solid line denotes LES data for flame HCO1 and dashed line denotes LES data for flame HCO2. 

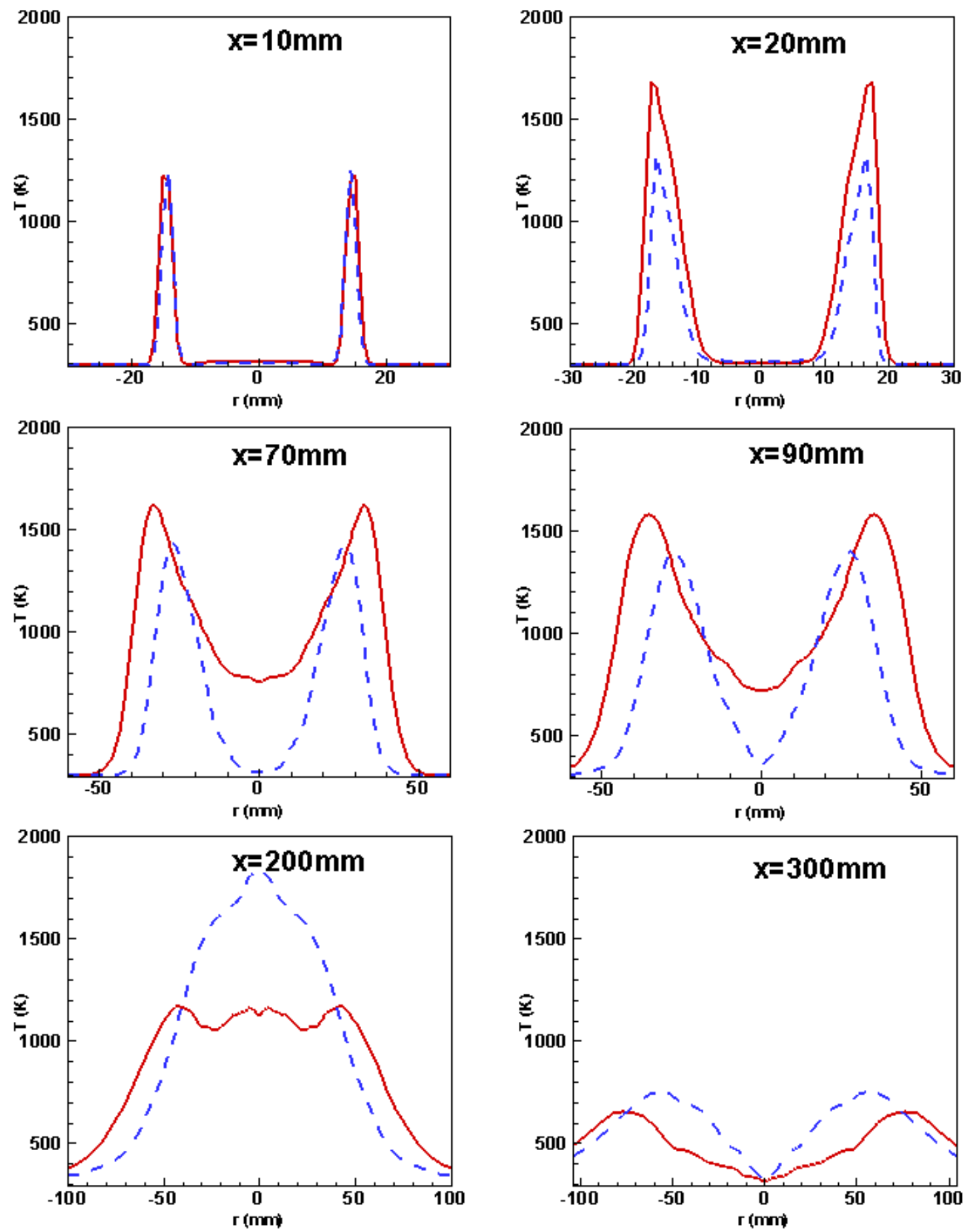

Fig.10. Time-averaged mean temperature for flames (a) HCO1 and (b) HCO2. Solid line denotes LES data for flame HCO1 and dashed line denotes LES data for flame HCO2. 

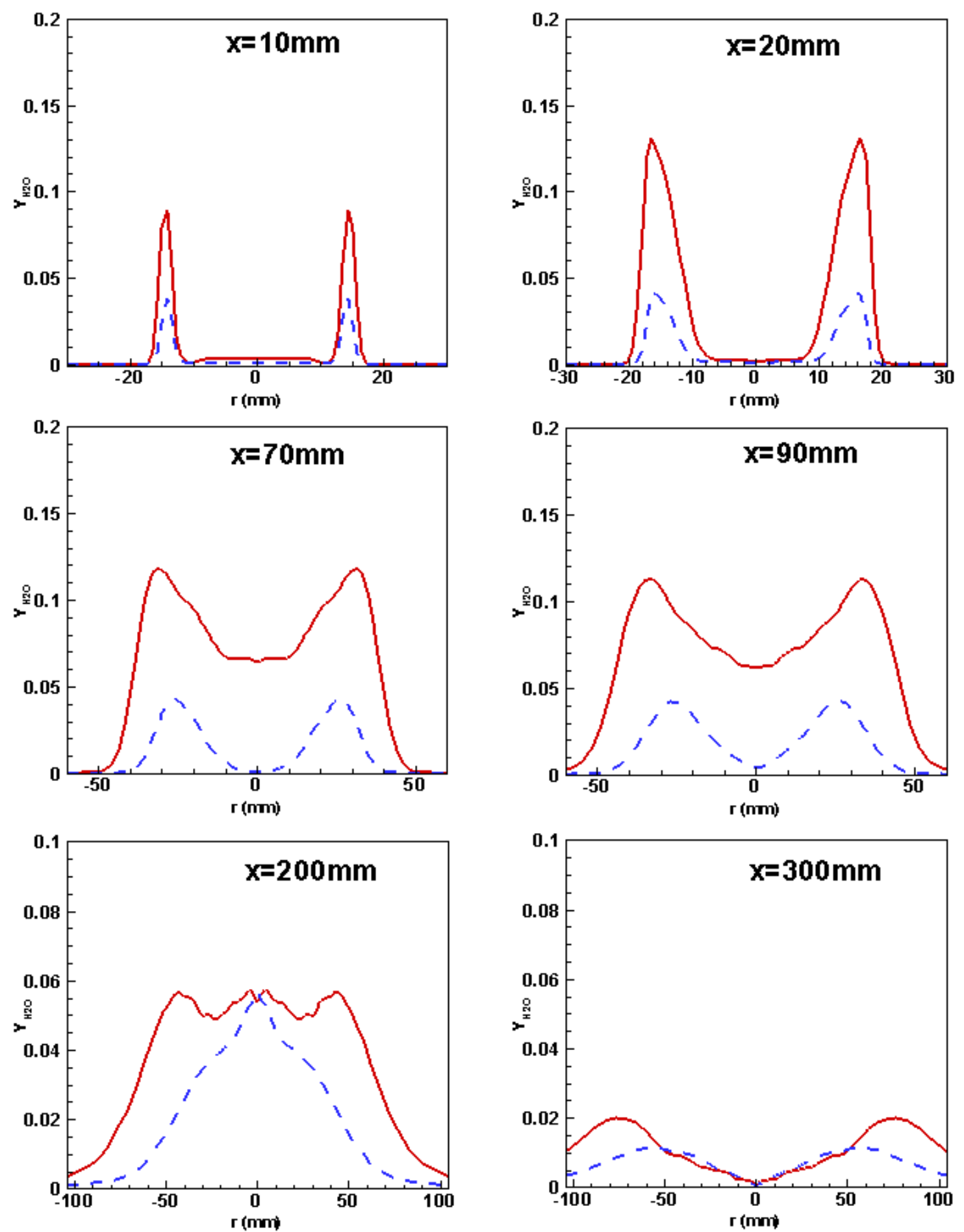

Fig.11. Time-averaged mass fraction of $\mathrm{H}_{2} \mathrm{O}$ for flames (a) $\mathrm{HCO} 1$ and (b) HCO2. Solid line denotes LES data for flame HCO1 and dashed line denotes LES data for flame HCO2. 

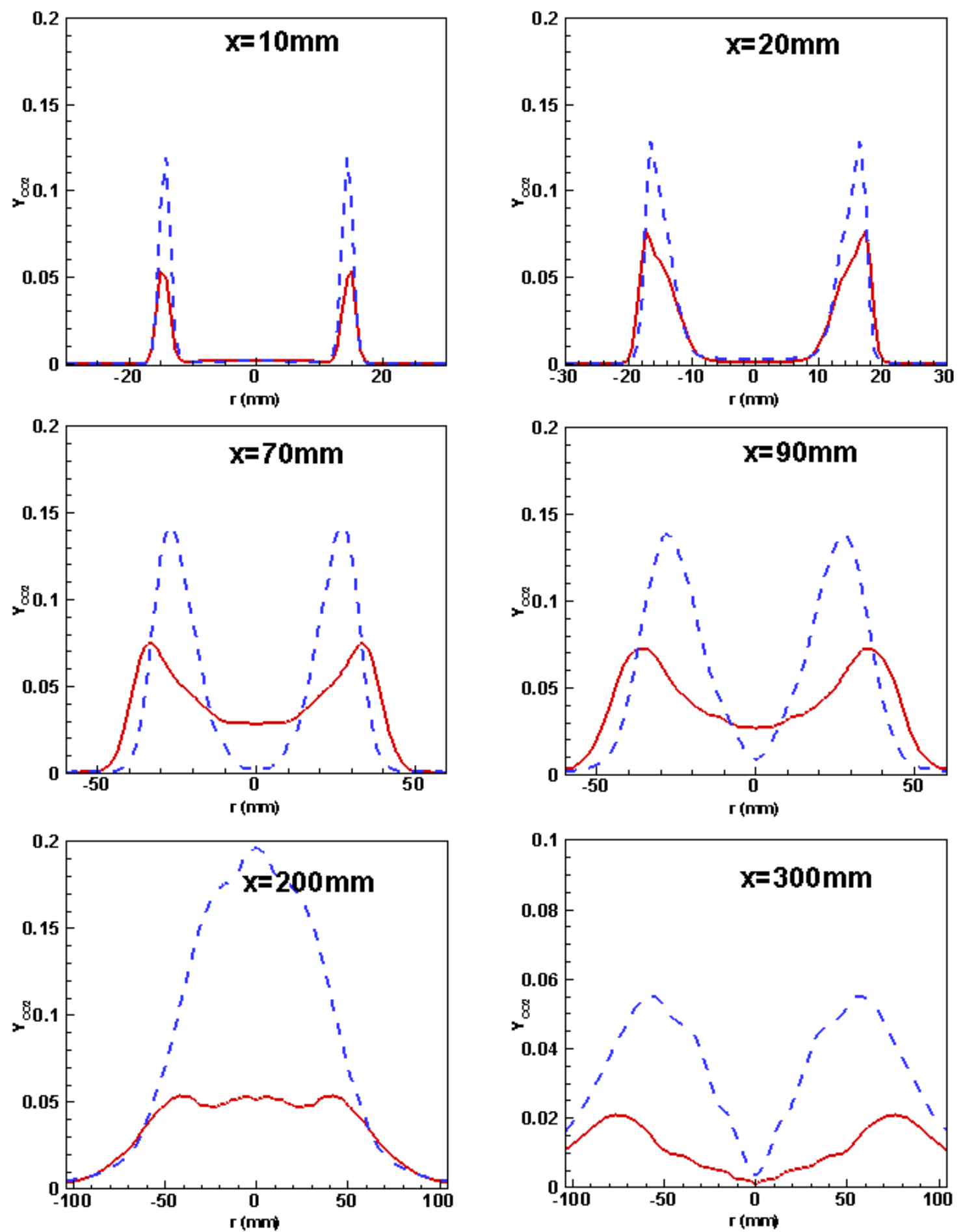

Fig.12. Time-averaged mass fraction of $\mathrm{CO}_{2}$ for flames (a) HCO1 and (b) HCO2. Solid line denotes LES data for flame HCO1 and dashed line denotes LES data for flame HCO2. 